\title{
Implementation of the Integrated School Information System Web- Based at the Teaching and Learning Activity Center (PKBM) in West Java
}

\author{
Implementasi Sistem Informasi Sekolah Terpadu Berbasis Web pada Pusat Kegiatan \\ Belajar Mengajar (PKBM) di Jawa Barat
}

\author{
Hapsari Widayani \\ hwidayani@gmail.com \\ Universitas Indraprasta PGRI
}

\begin{abstract}
The purpose of this study is to assist the teaching and learning process of administrative services and financial reporting in community learning activity centers with a well-integrated system. The data used are primary data. The data collection method used is direct observation on the research object, namely PKBM Patrakomala and PKBM Hiama. The method of analysis is descriptive qualitative analysis with the design based on web technology and MySQL for the database. The results in this study are that administrative services and financial reporting at PKBM use a well-integrated system so as to produce accountable and accurate financial reporting.

Keywords: accounting information system, center for teaching and learning activities, integrated systems Abstrak

Tujuan penelitian ini adalah untuk membantu proses belajar mengajar pelayanan administrasi dan pelaporan keuangan pada pusat kegiatan belajar masyarakat dengan sistem yang terintegrasai dengan baik. Data yang digunakan adalah data primer dengan metode pengumpulan data yang dilakukan adalah pengamatan langsung pada objek penelitian yaitu PKBM Patrakomala dan PKBM Hiama. Metode analisisnya adalah analisis deskriptif kualitatif dengan perancangannya berbasis teknologi web serta MySQL untuk basis datanya. Hasil dalam penelitian ini adalah pelayanan administrasi dan pelaporan keuangan pada PKBM menggunakan sistem yang terintegrasi dengan baik sehingga menghasilkan pelaporan keuangan yang akuntabel dan akurat.
\end{abstract}

Kata kunci: sistem informasi akuntansi, pusat kegiatan belajar mengajar, sistem terintegrasi

\section{PENDAHULUAN}

Meningkatnya kesadaran masyarakat terhadap pentingnya pendidikan, membuka mata kita bahwa pendidikan tidak hanya dapat dimaknai sebagai sekolah saja. Ia membutuhkan pengertian secara luas, bermakna, dan memberikan faedah bagi terbentuknya tatanan masyarakat, yang tidak hanya cerdas tapi juga berkarakter luhur (Sahlan, 2012). Definisi pendidikan menurut Undang-Undang Nomor 20 Tahun 2003 adalah usaha sadar dan terencana untuk mewujudkan suasana belajar dan proses pembelajaran agar peserta didik secara aktif mengembangkan potensi dirinya untuk memiliki kekuatan spiritual keagamaan, pengendalian diri, kepribadian, kecerdasan, akhlak mulia, serta keterampilan yang diperlukan dirinya, masyarakat, bangsa, dan negara.

Pendidikan pertama kali yang kita dapatkan adalah pada lingkungan keluarga. Keluarga berperan penting dalam membentuk karakter diri pada setiap anak. Pendidikan yang kedua atau setelah keluarga adalah sekolah. Lingkungan sekolah memberi peranan penting dalam mengajarkan anak perihal pendidikan formal dan nonformal. Pendidikan formal menurut 
Undang-Undang Nomor 20 Tahun 2003 adalah jalur pendidikan yang terstruktur dan berjenjang yang terdiri atas pendidikan dasar, menengah, dan tinggi. Sedangkan pendidikan nonformal adalah setiap kesempatan di mana terdapat komunikasi yang terarah di luar sekolah dan seseorang memperoleh info, pengetahuan, latihan maupun bimbingan sesuai dengan tingkat usia dan kebutuhan hidup dengan jutaan mengembangkan tingkat keterampilan, sikap, dan nilai - nilai yang memungkinkan baginya menjadi peserta-peserta yang efisien dan efektif dalam lingkungan keluarga, pekerjaan, bahkan lingkungan masyarakat, dan negaranya (Soelaman, 1992:51). Salah satu bentuk pendidikan nonformal adalah Pendidikan Kesetaraan Paket A, B, dan C pada pusat kegiatan belajar mengajar (PKBM), keaksaraan, pemberdayaan perempuan, pendidikan usia dini (PAUD), dan kegiatan ekstrakurikuler yang dilakukan di setiap sekolah.

Pusat kegiatan belajar mengajar (PKBM) adalah sebuah lembaga pendidikan yang diselenggarakan di luar sistem pendidikan formal, diarahkan untuk masyarakat pedesaan dan perkotaan dengan dikelola oleh masyarakat itu sendiri serta memberi kesempatan kepada mereka untuk mengembangkan berbagai model pembelajaran dengan tujuan mengembangkan kemampuan dan keterampilan masyarakat agar mampu meningkatkan kualitas hidupnya (Kamal, 2009:85). Pusat kegiatan belajar mengajar juga didefinisikan sebagai wadah yang dibentuk dari, oleh, dan untuk masyarakat dengan tujuan untuk meningkatkan pengetahuan dan keterampilan dengan memanfaatkan sarana, prasarana, dan potensi yang ada di sekitar lingkungannya (Firmansyah, 2012). Dari kedua definisi di atas maka PKBM merupakan wadah belajar bagi masyarakat yang dibentuk oleh masyarakat itu sendiri dengan memanfaatkan fasilitas yang ada untuk mencapai pembelajaran yang berkualitas dan memiliki keterampilan agar dapat meningkatkan kualitas hidupnya.

PKBM yang ada di Indonesia terutama di provinsi Jawa Barat tepatnya pada kota Bandung dan Depok terus mengalami peningkatan. Terlihat pada tahun 2017 jumlah PKBM yang dikelola oleh swasta di Kota Bandung sebanyak 111 sekolah dan di kota Depok sebanyak 48 sekolah. Data mengenai sekolah PKBM ada pada gambar 1. Sekolah PKBM ini akan terus meningkat sejalan dengan peningkatan kebutuhan akan pendidikan non formal bagi masyarakat sekitar yang terjangkau baik dari segi jarak dan biaya. Pendidikan non formal yang disediakan pada sekolah PKBM adalah paket kesetaraan A, B, dan C, serta keaksaraan. Paket A adalah pendidikan setara SD, Paket B adalah pendidikan setara SMP, dan Paket $\mathrm{C}$ adalah pendidikan setara SMA/SMK.

Kebutuhan akan sebuah sekolah non formal yang terjangkau oleh masyarakat harus diiringi oleh pelayanan yang baik seperti merekrut guru dan pegawai yang memiliki kemampuan serta kinerja yang baik, pemakaian sistem yang terintegrasi dengan baik, dan melakukan pengabdian terhadap masyarakat sekitar. Perekrutan guru dan pegawai yang berkompeten dibidangnya adalah dengan cara melakukan seleksi yang selektif sehingga menghasilkan guruguru dan pegawai yang sesuai disiplin ilmu dan dapat mengaplikasikan ilmu tersebut pada sekolah PKBM ini. Pemakaian sistem yang terintegrasi belum dilakukan sepenuhnya oleh PKBM sehingga dibutuhkan perancangan sistem yang baik dan mudah digunakan. Sistem yang terintegrasi ini memiliki tujuan yaitu untuk mendapatkan informasi yang berkualitas, cepat, akurat, dan tepat waktu. Di sisi lain, sekolah PKBM ini harus melakukan pengabdian masyarakat yaitu salah satunya memberikan pendidikan secara gratis bagi masyarakat yang kurang mampu. 


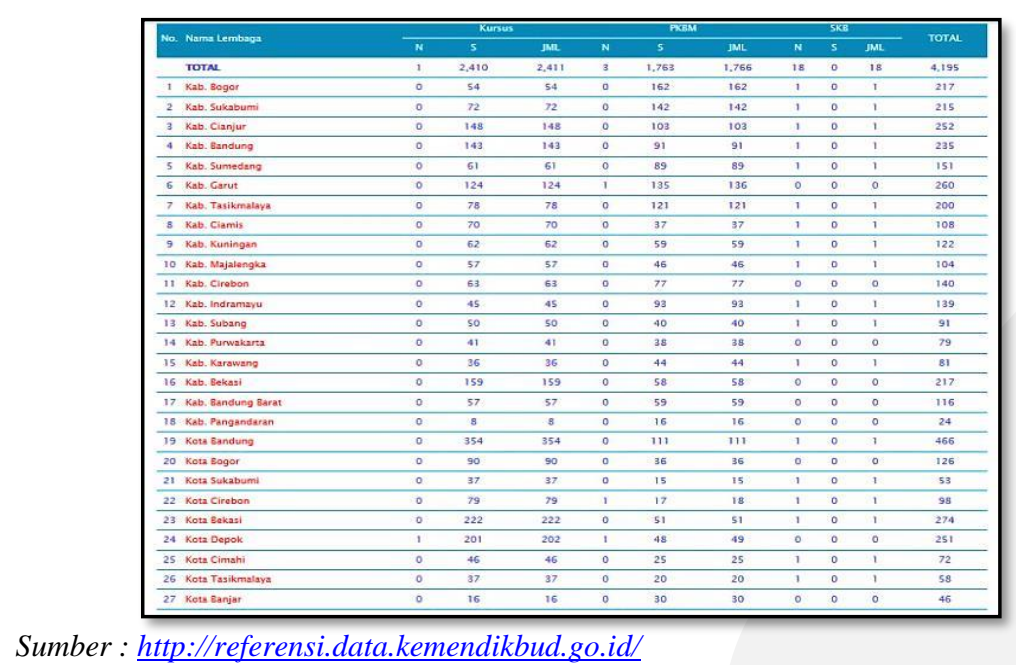

Gambar 1. Data Perkembangan Kursus dan PKBM di Provinsi Jawa Barat

Salah satu pusat kegiatan belajar mengajar (PKBM) yang memiliki pelayanan kurang baik adalah PKBM Patrakomala yang berada di Bandung dan PKBM Hiama yang berada di Depok. PKBM ini belum menggunakan sistem yang terintegrasi dengan baik. Sistem manual ini dilakukan mulai dari proses pendaftaran hingga pembuatan laporan keuangan. Sistem yang manual menyebabkan kualitas informasi yang dihasilkan belum cukup akurat dan prosesnya menjadi kurang cepat. Selain itu, sistem ini dapat menyebabkan kesalahan seperti pencatatan data yang berulang hingga menimbulkan inkonsisten data, data siswa yang lebih dari satu (double), dan kurang teliti saat pembuatan laporan keuangan. Oleh sebab itu, PKBM Patrakomala dan PKBM Hiama membutuhkan sistem informasi sekolah terpadu. Sistem informasi merupakan cara untuk menghasilkan informasi yang berguna, cepat, akurat, dan tepat waktu. Informasi yang berguna akan mendukung sebuah pengambilan keputusan bagi pemakainya dan melakukan tindakan secara tepat berdasarkan informasi yang dihasilkan tersebut (Noor, 2011).

Sistem terintegrasi yang disusun merupakan sistem administrasi dan keuangan sekolah. Sistem administrasi yang dibuat adalah input data mata pelajaran dan list ijazah untuk proses pengambilan ijazah siswa/i. Sistem keuangan sekolah yang dibuat adalah proses pembelian inventory, pembayaran operasional, pembayaran SPP dan ujian, dan pembayaran gaji karyawan.

Dengan adanya sistem informasi sekolah terpadu pada PKBM ini diharapkan dapat memberikan pelayanan yang prima kepada siswa dan orangtua sehingga memaksimalkan kinerja semua pegawai dan guru-guru.

\section{METODE}

Tempat kegiatan pengabdian masyarakat yaitu pada Pusat Kegiatan Belajar Mengajar (PKBM) Patrakomala yang beralamat di Jalan Nagrog III No. 106 RT 1 RW 9 Pasarjati, Ujungberung-Bandung dan Pusat Kegiatan Belajar Mengajar (PKBM) Hiama yang beralamat di Jalan Pondok Duta Raya No. 4 Tugu, Cimanggis-Depok. Waktu pelaksanaan kegiatan yaitu minggu kedua (2) bulan Juli 2018 hingga November 2018.

Metode yang akan digunakan dalam kegiatan ini adalah melalui beberapa tahap, 1) Pengamatan atau observasi, melakukan pengamatan terhadap kegiatan yang terjadi di PKBM Patrakomala dan PKBM Hiama, terutama pada bagian pendaftaran, bagian pelayanan 
administrasi, dan keuangan; 2) Wawancara, mengajukan sejumlah pertanyaan yang berhubungan dengan proses dan prosedur pelayanan sekolah terpadu pada PKBM Patrakomala dan Hiama. 3) Pelatihan dan sosialisasi, tim pelaksana pengabdian masyarakat melakukan pelatihan dan sosialisasi bagi pegawai dan guru-guru agar dapat menggunakan sistem yang telah dihasilkan dengan baik. Pelatihan ini dilakukan setelah sistem selesai dibuat dan dilakukan secara bertahap sehingga optimal hasilnya; 4) Hasil akhir, yang diberikan berupa sebuah publikasi ilmiah di jurnal/prosiding, sistem yang terintegrasi, dan manual book sebagai petunjuk penggunaan sistem. Sistem ini dibuat agar dapat digunakan secara optimal oleh pegawai dan guru-guru PKBM.

\section{HASIL DAN PEMBAHASAN}

\section{Hasil}

Diagram context adalah diagram yang terdiri dari suatu proses dan menggambarkan ruang lingkup suatu sistem. Diagram context merupakan level tertinggi dari Data Flow Diagram (DFD) yang menggambarkan seluruh input ke sistem atau ouput dari sistem. Dari diagram context di bawah ini menunjukkan bahwa sistem informasi sekolah terpadu diawali siswa melakukan pendaftaran dengan memberikan informasi tentang data diri secara detail kemudian data diri siswa baru tersebut diolah oleh sistem dan menghasilkan data diri siswa baru. Setelah proses pendaftaran selesai, siswa melakukan proses pembayaran. Proses ini menghasilkan kuitansi pendaftaran dan database siswa baru. Proses selanjutnya adalah pembayaran SPP dan ujian. Proses ini membutuhkan input data siswa baru dan lama dan menghasilkan sebuah output yakni kuitansi pembayaran yang diserahkan kepada siswa. Selanjutnya adalah proses input jadwal mata pelajaran dan list ijazah ke sistem oleh tata usaha dan menghasilkan sebuah output yaitu persetujuan laporan jadwal mata pelajaran dan list ijazah.

Proses keuangan di sekolah ini adalah pembelian inventory, pembayaran operasional, dan pembayaran gaji karyawan yang dilakukan oleh bendahara. Input dari semua proses ini adalah kuitansi pembelian inventory, kuitansi pembayaran operasional, dan kuitansi pembayaran gaji. Semua input ini diolah ke sistem dan akan menghasilkan laporan yang diserahkan kepada kepala sekolah dan jika kepala sekolah telah menyetujui diserahkan kembali kepada sistem dan sistem akan memberikan kembali data pembelian, data pembayaran operasional, dan data gaji karyawan kepada bendahara. Semua laporan yang telah diterima oleh kepala sekolah diberikan kepada yayasan agar diperiksa dan diarsipkan. Hal ini terlihat pada gambar di bawah ini.

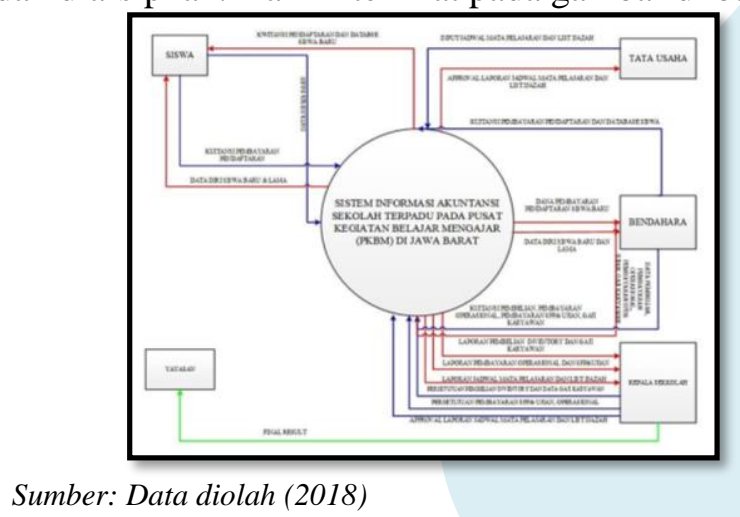

Gambar 2. Diagram Context Sistem Informasi Sekolah Terpadu Pusat Kegiatan Belajar Mengajar (PKBM) Pada Sistem yang Berjalan

Implementation of the Integrated School Information System Web-Based at the Teaching and Learning Activity Center (PKBM) in West 
Pada alur administrasi dan keuangan di pusat kegiatan belajar mengajar, diawali dengan proses pertama yakni proses pendaftaran dan pembayaran. Pada proses pendaftaran dan pembayaran, siswa menyerahkan data diri siswa baru kepada sistem. Sistem akan memprosesnya dan diberikan data tersebut kepada bendahara serta menyimpannya pada database data siswa baru. Bendahara yang sudah melakukan verifikasi data siswa baru akan memberikan kuitansi pendaftaran kepada sistem yang selanjutnya akan diserahkan kepada siswa untuk melakukan proses pembayaran. Proses kedua adalah proses pembayaran SPP dan ujian. Proses pembayaran SPP dan ujian ini dilakukan oleh siswa baru dan siswa lama. Siswa menyerahkan data diri siswa ke sistem lalu oleh sistem di olah dan di berikan kepada bendahara. Bendahara akan mengeluarkan kuitansi pembayaran. Kuitansi pembayaran itu diserahkan kepada siswa. Proses ketiga adalah proses pembelian inventory. Proses ini dilakukan oleh bendahara dan melaporkannya ke kepala sekolah. Bendahara melakukan input data pembelian inventory ke sistem dan oleh sistem dilaporkan kepada kepala sekolah agar disetujui. Jika sudah disetujui, bendahara melakukan proses pembelian inventory dan kuitansi pembelian di-input ke sistem agar dapat dibuat laporan pembelian inventory dan diserahkan kepada kepala sekolah. Proses keempat adalah proses pembayaran operasional. Bendahara melakukan proses pembayaran dan menyerahkan kuitansi pembayaran operasional kepada sistem dan sistem akan mengolahnya menjadi sebuah laporan pembayaran operasional dan diserahkan kepada kepala sekolah. Kepala sekolah menyetujui pembayaran operasional melalui sistem dan sistem akan mengeluarkan data pembayaran operasional dan memberikannya kepada bendahara. Proses kelima adalah proses pembayaran gaji. Bendahara menyerahkan kuitansi pembayaran gaji karyawan kepada sistem. Sistem mengolahnya menjadi laporan gaji karyawan dan melaporkan kepada kepala sekolah. Kepala sekolah melakukan validasi data gaji karyawan kepada sistem. Sistem selanjutnya menyerahkan data gaji karyawan untuk di arsipkan. Proses terakhir adalah proses administrasi yaitu bagian tata usaha melakukan input data jadwal mata pelajaran dan list ijazah ke sistem dan sistem meneruskan kepada kepala sekolah untuk mendapatkan persetujuan. Jika kepala sekolah sudah setuju maka persetujuan laporan jadwal mata pelajaran dan list ijazah dikembalikan ke bagian tata usaha. Langkah selanjutnya adalah semua data yang berada di kepala sekolah diserahkan kepada yayasan untuk diperiksa dan diarsipkan.

\section{Usulan Diagram Context Sistem Informasi Akuntansi Penerimaan dan Pengeluaran Kas pada Pusat Kegiatan Belajar Mengajar (PKBM)}

Diagram context di bawah ini menunjukkan bahwa usulan sistem informasi sekolah terpadu diawali siswa melakukan pendaftaran dengan memberikan informasi tentang data diri secara detail kemudian data diri siswa baru tersebut diolah oleh sistem dan menghasilkan data diri siswa baru dan formulir tanda terima siswa baru. Setelah proses pendaftaran selesai, siswa melakukan proses pembayaran. Proses ini menghasilkan bukti pembayaran pendaftaran. Proses selanjutnya adalah pembayaran SPP dan ujian. Proses ini membutuhkan input data siswa baru dan lama dan menghasilkan sebuah output yakni bukti pembayaran SPP dan ujian yang diserahkan kepada siswa. Proses selanjutnya adalah pembelian inventory, pembayaran operasional, dan pembayaran gaji karyawan yang dilakukan oleh bagian keuangan. Input dari semua proses ini adalah bukti pembayaran pembelian inventory, bukti pembayaran operasional, dan bukti pembayaran gaji. Semua input ini diolah ke sistem dan akan menghasilkan laporan yang diserahkan kepada bagian akuntansi dan bagian akuntansi akan membuat laporan keuangan berdasarkan input tersebut. Sedangkan bagian keuangan akan mendapatkan data - data pembayaran berupa data pembayaran pembelian inventory, pembayaran operasional, dan 
pembayaran gaji. Selanjutnya adalah proses input jadwal mata pelajaran dan list ijazah ke sistem oleh tata usaha dan menghasilkan sebuah output yaitu persetujuan laporan jadwal mata pelajaran dan list ijazah.

Proses selanjutnya adalah penyerahan laporan keuangan kepada kepala sekolah. Kepala sekolah melakukan validasi laporan keuangan tersebut dan diserahkan kembali ke bagian akuntansi untuk di arsipkan. Semua laporan yang telah diterima dan di validasi oleh kepala sekolah diberikan kepada yayasan agar dapat diperiksa Hal ini terlihat pada gambar dibawah ini.

\section{Entity Relationship Diagram Sistem Informasi Akuntansi Penerimaan dan Pengeluaran Kas pada Pusat Kegiatan Belajar Mengajar (PKBM)}

Berdasarkan data flow diagram (DFD) yang telah dibuat sebelumnya, Entity Relationship Diagram (ERD) dari sistem informasi sekolah terpadu pada pusat kegiatan belajar mengajar terdiri dari 9 proses. Proses yang pertama adalah pendaftaran siswa baru, proses kedua adalah proses pembayaran pendaftaran siswa baru, proses ketiga adalah proses pembayaran SPP dan ujian, proses keempat adalah proses pembelian inventory, proses kelima adalah proses pembayaran operasional, proses keenam adalah proses pembayaran gaji, proses ketujuh adalah proses input dan approval jadwal mata pelajaran dan list ijazah, proses kedelapan adalah proses pembuatan laporan keuangan, dan proses terakhir adalah proses penyerahan laporan keuangan. Adapun Entity Relationship Diagram tersebut dapat dilihat pada gambar di bawah ini.

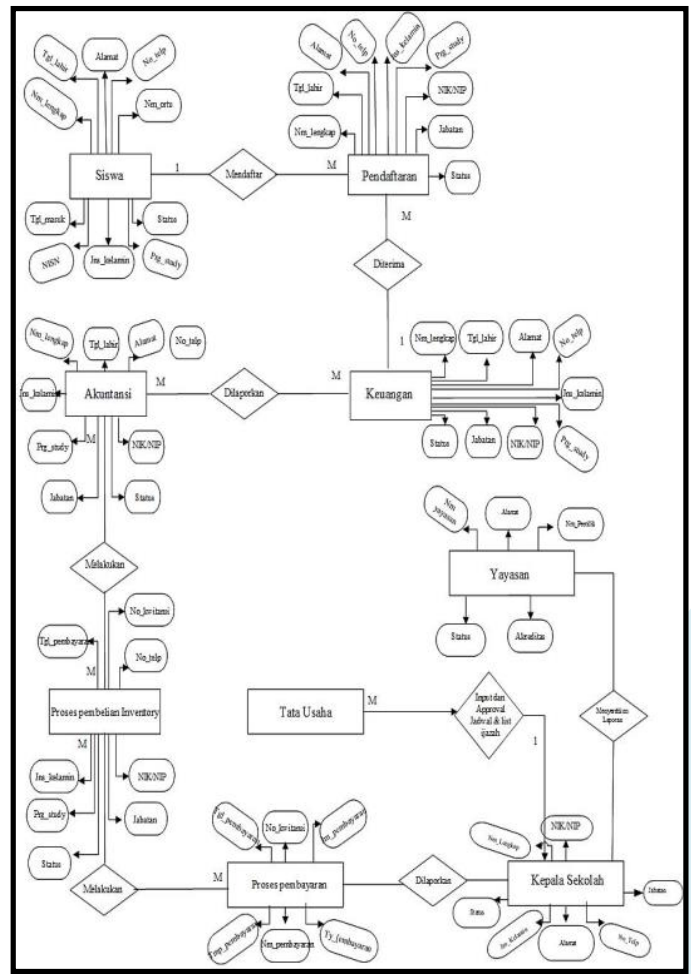

Gambar 6. Entity Relationship Diagram Sistem Informasi Sekolah Terpadu pada Pusat Kegiatan Belajar Mengajar (PKBM) di Jawa Barat 
Implementation of the Integrated School Information System Web-Based at the Teaching and Learning Activity Center (PKBM) in West Java

Hapsari Widayani

https://doi.org/10.37010/nuc.v1i1.79

\section{Prototype Aplikasi Sistem Informasi Sekolah Terpadu pada Pusat Kegiatan Belajar} Mengajar (PKBM)

Desain yang dirancang berdasarkan diagram alur data flow diagram dan database entity relationship diagram adalah sebagai berikut :

\section{Form Home}

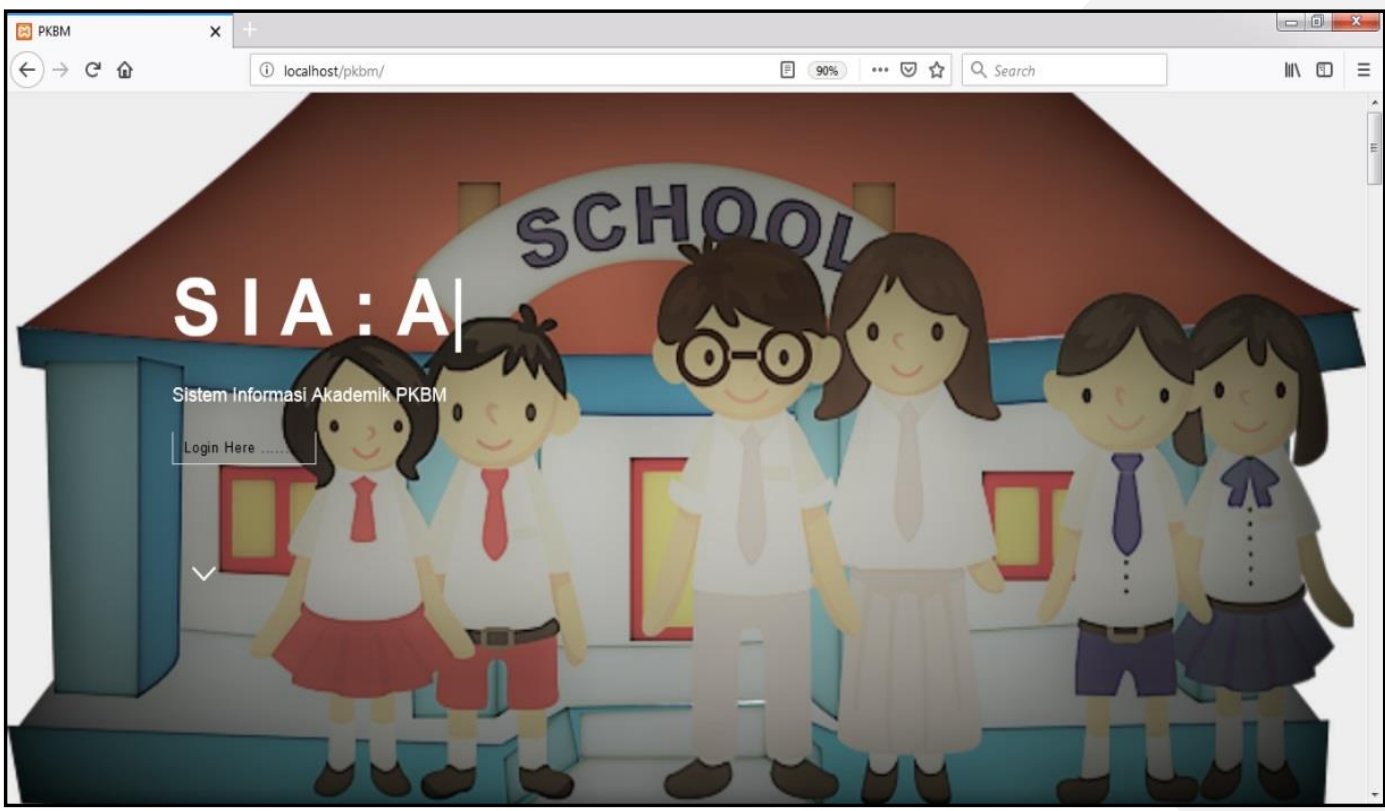

Sumber: Data Diolah (2018)

Gambar 7. Form Home

Form Profile

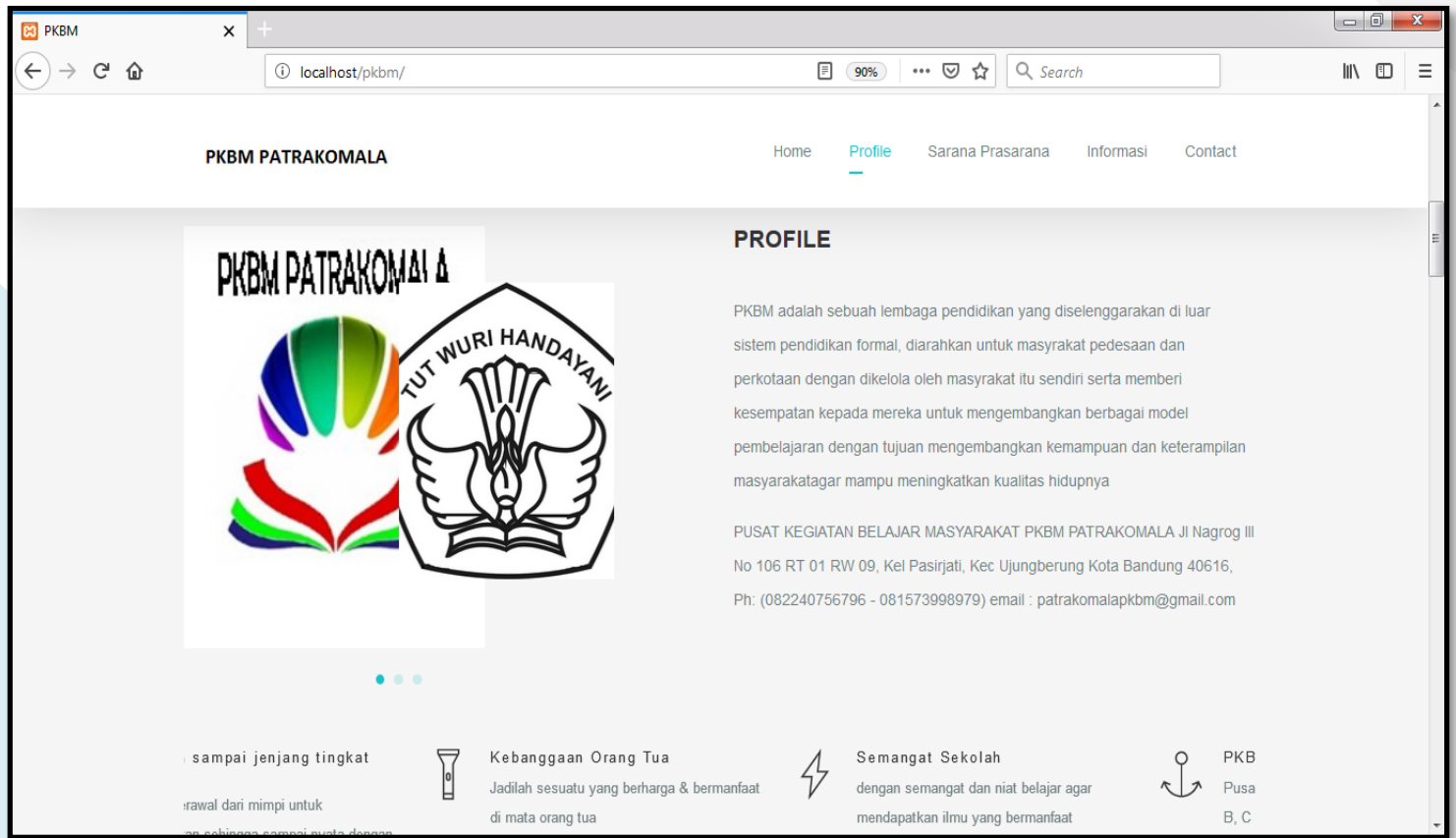

Gambar 8. Form Profile 


\section{PENUTUP}

Kegiatan pengabdian masyarakat yang dilakukan ini sangat perlu dan dirasakan manfaat bagi peningkatan proses pelayanan pendaftaran hingga pengolahan data keuangan. Kegiatan ini juga memberikan kontribusi positif untuk menciptakan sebuah desain yang terarah dan terstruktur dengan baik. Maka dari itu, kegiatan ini dapat disimpulkan sebagai berikut:

1. Pusat kegiatan belajar mengajar sudah memiliki sebuah sistem administrasi dan keuangan yang terintegrasi dengan baik. Sistem ini disusun oleh tim pengabdian masyarakat menyesuaikan dengan kebutuhan PKBM Patrakomala dan PKBM Hiama.

2. Pengolahan data administrasi dan keuangan sudah menggunakan sebuah sistem yang userfriendly dan memudahkan pengguna untuk mengambil sebuah keputusan.

3. Guru-guru dan staf PKBM sudah dapat mengaplikasikan desain ini dengan baik sesuai dengan knowledge yang telah ditransfer oleh tim pengabdian masyarakat.

Untuk memperbaiki kelemahan pada sistem yang telah dibuat maka penulis memberikan beberapa usulan sebagai berikut:

1. Perlu diadakan pelatihan berkala dan perbaikan jika terdapat sistem yang tidak sesuai dengan kebutuhan PKBM.

2. Diharapkan nantinya sistem ini dijadikan diaplikasikan dengan baik untuk memudahkan pelayanan terhadap siswa, orang tua, guru-guru, dan yayasan.

\section{DAFTAR PUSTAKA}

Anhar. 2010. Panduan Menguasai PHP dan MySQL. Jakarta : Media Kita.

Bodnar,George H dan William S.Hoopwood. 2006. Sistem Informasi Akuntansi. Edisi Kesembilan. Yogyakarta : Penerbit Andi.

Hall, James A. 2012. Sistem Informasi Akuntansi. Volume 1. Jakarta : Salemba Empat.

Hapsari, Septika, et all. 2012. Rancang Bangun Sistem Informasi Pembayaran dan Tabungan Siswa Pada Bank Mini Artha Mandiri Sekolah Menengah Kejuruan (SMK) Negeri Pringkuku Pacitan. Indonesian Journal on Computer Science Speed-FTI UNSA. Vol.9 No.3

Ibrahim, Ali. 2008. Cara Praktis Membuat Website Dinamis Menggunakan XAMPP. Yogyakarta: Neotekno.

Jogiyanto HM. 2010. Analisis dan Desain Sistem Informasi (Pendekatan Terstruktur Teori dan Praktek Aplikasi Bisnis). Yogyakarta : Penerbit Andi.

Kamal, Mustafa. 2009. Pusat Kegiatan Belajar Masyarakat Dalam Pendidikan Luar Sekolah. Tersedia di: http:// http://pkbm-harapan-bangsa.blogspot.co.id/2017/04/pusat-kegiatanbelajar-masyarakat-dalam-pendidikan-luar-sekolah.html, diakses pada 6 Mei 2018 Jam 06.30 .

Noor S, Fuad. 2011. Implementasi Sistem Informasi Rumah Sakit Untuk Subsistem Farmasi. Jurnal Seminar Tugas Akhir.

Romney, Marshall B dan Paul John Steinbart. 2016. Accounting Information System. Buku Kesatu. Edisi Kesembilan. Jakarta : Salemba Empat. 
Sahlan, Asmaun dan Angga Teguh Prasetyo. 2012. Desain pembelajaran berbasis pendidikan karakter. Yogyakarta : Ar-Ruzz Media.

Soelaman, Joesoef. 1992. Konsep Dasar Pendidikan Non Formal. Jakarta : Bumi Aksara.

Sutisna, Deny Firmansyah. 2012. Peranan Pusat Kegiatan Belajar Masyarakat (PKBM) dalam Menumbuhkan Minat Baca Warga Belajar. Jurnal Mahasiswa Universitas Padjajaran. Vol.1 No.1.

Widayani, Hapsari. 2016. Analisis dan Perancangan Sistem Informasi Akuntansi Pelayanan Pasien Rawat Jalan dan Rawat Inap Pada Rumah Bersalin dan Klinik Gebang Medika. Thesis. Program Pascasarjana Universitas Gunadarma.

Yuhifezar. 2008. 10 Jam Menguasai Internet. Jakarta : PT Elex Media Komputindo. 